\title{
INVESTIGACIONES
}

\section{Demandas cognitivas de la escritura: comparación de dos situaciones de producción}

\author{
Cognitive demands of writing: comparison of two \\ different situations of production
}

\section{Exigências cognitivas da escritura: comparação de duas situações de produção}

\author{
Verónica Sánchez ${ }^{1 *}$, Valeria Moyano ${ }^{2 *}$, A. María Borzone ${ }^{3 *}$ \\ ${ }^{1}$ Consejo Nacional de Investigaciones Científicas y Técnicas (CONICET). Vsanchezabchi@yahoo.com.ar \\ ${ }^{2}$ Centro de Investigaciones Lingüísticas. Universidad Nacional de Córdoba. Val_aspis@hotmail.com \\ ${ }^{3}$ CIIPME-Consejo Nacional de Investigaciones Científicas y Técnicas (CONICET). anabor@arnet.com.ar \\ *Centro de Investigaciones Lingüísticas. Facultad de Lenguas. Universidad Nacional de Córdoba. Vélez \\ Sársfield 187. X5000 JJB Córdoba Capital. Argentina. 5403514331073 interno 15. cil@ fl.unc.edu.ar
}

\begin{abstract}
RESUMEN
El presente trabajo tiene por objeto analizar las narraciones escritas de un grupo de niñas hablantes de español, que cursan $2^{\circ}$ grado de la E.G.B., en una escuela privada de Córdoba, Argentina. Las narraciones han sido producidas en dos situaciones que plantean demandas cognitivas diferenciadas: a) a partir de una narración oral y b) a partir de una secuencia de imágenes. Para el análisis de las narraciones se consideró la extensión, la cantidad de categorías narrativas recuperadas (Stein y Glenn, 1979), el empleo de mecanismos de cohesión y de fórmulas de ficción. Los resultados mostraron que el desempeño fue superior en las narraciones producidas a partir de imágenes. El trabajo discute, también, las demandas cognitivas de las tareas y sus posibles implicancias pedagógicas.
\end{abstract}

Palabras clave: producción de textos, narraciones escritas, demandas cognitivas de la escritura.

\begin{abstract}
This work aims to analyze the written stories produced by Spanish speaking girls of second grade in primary education. The children attended a private school from Cordoba Province, Argentine. The stories were produced under two conditions with different cognitive demands: a) retelling of an oral story, and b) telling a story from a sequence of pictures. The texts were analyzed considering length, the number of narrative categories recovered (Stein y Glenn, 1979), the employment of cohesion mechanisms and the inclusion of fiction formulae The results showed that the performance was better in the stories produced from pictures. This paper also discusses the cognitive demands of the tasks and their possible pedagogical implications.

Key words: text production, written narratives, cognitive demands of writing.

\section{RESUMO}

Este trabalho tem como finalidade analisar as narrações escritas em espanhol por um grupo de meninas que freqüentam o segundo ano de ensino primário numa escola privada de Córdoba, Argentina. As narrações foram produzidas em duas situações que apresentam diferentes exigências cognitivas: a) a partir de uma narração oral e b) a partir de uma seqüência de imagens. Para a análise dos textos foi considerada a extensão, a quantidade de categorias narrativas recuperadas (Stein e Glenn, 1979), bem como o emprego de mecanismos de coesão e fórmulas da ficção. Os resultados demonstram que o desempenho foi superior nas narrações produzidas a partir de imagens. O trabalho também discute as exigências cognitivas das tarefas e suas possíveis implicações pedagógicas.
\end{abstract}

Palavras-chave: produção de textos, narrações escritas, demandas cognitivas da escrita. 


\section{INTRODUCCION}

El presente trabajo tiene por objeto analizar las narraciones escritas de un grupo de alumnas de $2^{\circ}$ grado de la E.G.B., producidas en distintas situaciones que plantean demandas cognitivas diferenciadas.

En el marco de los modelos cognitivos de escritura, la producción de textos escritos supone diferentes procesos: la planificación -que incluye la generación de las ideas, su jerarquización y organización-, la traducción -es decir, la puesta en texto- y la revisión (Hayes y Flower, 1980; Bereiter \& Scardamalia, 1987). Asimismo, Berninger y colaboradores $(1992 ; 1994)$ distinguen, dentro del proceso de traducción, dos subprocesos: la transcripción y la generación textual. El proceso de generación textual implica poner las ideas en lenguaje, mientras que la transcripción supone la transformación del lenguaje oral en lenguaje escrito. En este sentido, la transcripción incluye habilidades básicas tales como la codificación fonológica, el trazado de las letras y la escritura de palabras. En su conjunto, todos estos procesos realizan múltiples demandas cognitivas al sistema de memoria. En el inicio del aprendizaje de la escritura, cuando las habilidades básicas -también llamadas de nivel inferior- no están aún automatizadas, la transcripción requiere de muchos recursos atencionales que restan recursos a los demás procesos implicados en la tarea de escritura. Las demandas extras pueden generar una situación de sobrecarga de la memoria operativa -que tiene una capacidad de procesamiento limitada-, lo que puede afectar el desempeño en la tarea de escritura (Para una revisión, Bourdin, Fayol \& Darcieux, 1996; Sánchez Abchi, 2009, para el español).

Asimismo, la sobrecarga cognitiva puede producirse cuando las operaciones de generación de ideas, jerarquización de la información, estructuración, etc., no han sido ejercitadas suficientemente, de forma tal que las demandas cognitivas que cada proceso plantea a la memoria son tan costosas en términos atencionales que afectan la calidad y la extensión de las producciones (Berninger \& Swanson, 1994; Berninger, Yates, Cartwright, Rutberg, Remz \& Abbott, 1992).

Es por ello que, durante el aprendizaje, resulta importante facilitar al niño instrumentos que le permitan aliviar la situación de sobrecarga cognitiva, hasta que pueda alcanzar cierto nivel de maestría en la tarea de producción textual. En este sentido cobra especial relevancia el concepto de andamiaje docente, es decir, un apoyo discursivo que, en la interacción, le permite al niño llevar a cabo, en colaboración con el adulto, una actividad que no podría realizar solo (Brunner, 1986). El andamiaje constituye, pues, una posibilidad de facilitar la tarea de escritura de textos. Otro camino consiste en proponer al niño tareas con diferente grado de complejidad, de forma tal que el escritor principiante pueda apropiarse de las estrategias de escritura experta en la realización y práctica de tareas sencillas, estrategias que luego puedan aplicarse en situaciones de escritura más complejas. De ahí el interés por explorar si algunas tareas de composición pueden aliviar las demandas cognitivas de la escritura, especialmente en los primeros años de aprendizaje.

El impacto que la tarea tiene en el desempeño en la producción de textos ha sido objeto de numerosos estudios. Sin embargo, particularmente en inglés, los resultados encontrados no han sido siempre coincidentes respecto de las demandas de cada tarea. Por su parte, en español, la incidencia que las características de la tarea tienen en la producción de textos ha sido poco explorada. 
Pratt y Mac Kenzie-Keating (1985) estudiaron el efecto que la posible dificultad de la tarea tenía en la cohesión referencial de textos narrativos producidos oralmente por niños de 4 y 6 años. Entre otras variables, compararon el efecto de una historia presentada verbalmente vs. una historia presentada en video. Los resultados indicaron que los errores en cohesión fueron mayores en la historia renarrada a partir de un input con video que en la historia producida a partir de un input verbal.

Por su parte, Schneider (1996) analizó los textos narrativos orales producidos por niños de 5 a 9 años con dificultades de lenguaje, en tres condiciones diferentes: a) a partir de imágenes; b) a partir de una historia presentada oralmente y c) a partir de un estímulo verbal y de imágenes. El autor observó un desempeño significativamente superior en las narraciones producidas a partir de imágenes, sin apoyo de la narración oral.

Pero Gazella y Stockman (2003) obtuvieron resultados diferentes. Estudiaron también el posible efecto de la modalidad de presentación de la historia en el desempeño de niños de 4 a 6 años. Compararon dos condiciones de presentación: sólo oral y oral combinado con visual. Observaron que no hubo diferencias significativas entre ambas condiciones.

En un estudio similar, Schneider y Dubé (2005) compararon las producciones de niños de nivel inicial y de $2^{\circ}$ grado, a partir de tres condiciones diferentes de presentación: a) sólo oral; b) sólo con imágenes y c) combinación de presentación oral e imágenes. Los niños de ambas edades obtuvieron mejores resultados cuando renarraron historias presentadas en la modalidad combinada. Asimismo, recuperaron más información narrativa en la condición sólo oral que en la condición sólo con imágenes.

En los trabajos citados se ha atendido a la producción oral. Sin embargo, el impacto de la tarea en la producción escrita no ha sido aún abordado en profundidad. Borzone y Marro (1990) observaron que los textos escritos por un grupo de niños, a comienzos de segundo grado, eran más completos cuando se trataba de la renarración de un cuento leído que cuando se realizaba a partir de una secuencia de imágenes. Las autoras atribuyen las diferencias al hecho de que el cuento leído era breve, tenía un solo episodio y las imágenes no presentaban todas las categorías de la estructura narrativa, hecho que obligaba a los niños a planificar y reponer una escena, un evento inicial y una respuesta interna, según las categorías de Stein y Glenn (1979).

Con el objeto de explorar la incidencia de la situación de escritura en el desempeño de los niños, en este trabajo comparamos las narraciones escritas por niñas de $2^{\circ}$ grado en dos condiciones diferentes: a) a partir de una narración oral y b) a partir de una secuencia de imágenes. Se buscó homologar los textos en cuanto a su complejidad estructural y tipo de eventos.

Ambas tareas plantean demandas cognitivas diferentes. En efecto, facilitar al niño un modelo escrito, a través de la lectura, que luego deberá recuperar en su producción escrita, puede disminuir el esfuerzo cognitivo de planificación y textualización. Asimismo, la producción de una historia a partir de imágenes constituye otra modalidad de apoyo, que facilita la planificación.

En el presente trabajo nos propusimos indagar cuál de estas dos tareas resultaba cognitivamente menos costosa y favorecía la producción escrita. Se hipotetizó que la escritura a partir de un input verbal resultaría menos demandante porque facilitaba a los alumnos un modelo de textualización. 


\section{METODOLOGIA}

\section{SUJETOS}

Participaron de la experiencia 34 niñas, edad promedio 7.3 (extremos 6.9 y 8.3 años) de $2^{\circ}$ grado que concurrían a una escuela privada de clase media de la ciudad de Córdoba, Argentina. La producción escrita fue realizada sólo por niñas porque la escuela no era mixta.

\section{PRUEBAS Y PROCEDIMIENTO}

Con el objeto de evaluar las habilidades de producción escrita de las niñas y comparar el desempeño en condiciones diferentes, se aplicaron dos pruebas de escritura: una prueba de renarración escrita y una prueba de narración escrita a partir de imágenes.

\section{PRUEBA DE RENARRACION ESCRITA:}

Se les narró a las niñas un cuento de estructura canónica: "El león y el elefante" (Sánchez Abchi, Borzone y Diuk, 2007). De acuerdo a las categorías narrativas de Stein y Glenn (1979), el cuento se estructuraba en dos episodios, cada uno con seis categorías. Se les pidió a las alumnas que prestaran mucha atención al cuento que se les iba a leer, ya que luego de la lectura deberían escribir ellas mismas el cuento.

\section{PRUEBA DE NARRACION ESCRITA A PARTIR DE IMAGENES:}

Se les presentó a las niñas una serie de trece imágenes, que mostraban los eventos de una narración con estructura canónica, de dos episodios: "El cabrito y el león". Cada imagen representaba una categoría narrativa del cuento (Stein y Glenn, 1979). La prueba, realizada en entrevistas individuales, consistió en que las niñas observaran las imágenes y escribieran luego la historia, con las imágenes presentes.

Las pruebas fueron aplicadas con una semana de diferencia.

\section{ANALISIS DE LA INFORMACION EMPIRICA}

Para el análisis de las narraciones producidas en ambas pruebas se consideró la extensión de las producciones, medida en cantidad de palabras completas, sin omisión de letras y cantidad de categorías narrativas recuperadas, siguiendo el esquema de Stein y Glenn (1979). Se consideró también la cantidad de palabras intentadas, es decir, palabras incompletas, con omisiones de letras. Las palabras intentadas constituyen un indicador complementario del nivel de dificultad que pueden tener los niños en los procesos de transcripción (Sánchez Abchi, Borzone y Diuk, 2007).

Se tuvieron en cuenta también indicadores de la calidad de la superficie textual: empleo de conectores, de tiempos verbales, de mecanismos de correferencia y de fórmulas de ficción.

Con respecto a la cohesión textual se observó el empleo de conectores y el mantenimiento de la cadena de correferencia. En el análisis de los conectores se consideró la 
frecuencia de aparición de los conectores temporales, causales, adversativos y aditivos. Si bien la ausencia absoluta de conectores no es, necesariamente, un indicador de un menor dominio en el uso de estos mecanismos lingüísticos, en este trabajo se ha adoptado como criterio asignar puntaje cero a las producciones que no incluyen ningún conector; producciones que son generalmente las formadas por una sola cláusula.

Para el análisis de los mecanismos de correferencia se consideraron sólo las expresiones referenciales en posición de sujeto agente. Se tomó la codificación de Schneider y Dubé (1997) adaptada al español para este trabajo. Cada expresión referencial para introducir un personaje o para mantener la referencia fue clasificada como "adecuada o inadecuada" de acuerdo a los siguientes criterios:

Una expresión referencial usada para presentar un referente por primera vez se consideró adecuada si se utilizaba un nombre propio o una frase nominal con artículo indefinido. Las expresiones de presentación de referente con artículo definido, sin artículo alguno, los pronombres o las elipsis fueron codificadas como inadecuadas.

Las expresiones que aludían a un referente ya introducido fueron consideradas adecuadas si se remitían con claridad a dicho referente. Las elipsis ambiguas, los pronombres ambiguos o el uso de un ítem léxico diferente fue codificado como inadecuado.

Para calcular el puntaje de adecuación referencial para cada relato producido por una niña, se dividió el número de expresiones referenciales adecuadas por el número total de expresiones referenciales incluidas en el relato escrito por el niño.

El análisis de los tiempos verbales atendió puntualmente al empleo adecuado de las formas conjugadas en el contexto narrativo, de acuerdo a las reglas de concordancia en español, específicamente, la relación de consecutio temporum. Se considera la relación de consecutio temporum como una "relación de dependencia entre las interpretaciones temporales de dos formas verbales si entre sus respectivas oraciones existe una relación de dependencia o subordinación [...] y el [verbo] primero orienta sus relaciones temporales respecto al segundo" (Carrasco Gutiérrez, 1999: 3063).

Se atendió también a criterios de mantenimiento de la referencia temporal en la narración, esto es, el mantenimiento del tiempo verbal elegido para narrar en oposición a la alternancia entre presente y pasado (Sebastián y Slobin, 1994). Para este análisis se consideró cuál era el tiempo predominante, es decir, el más frecuente en cada narración, de acuerdo a los criterios de Sebastián (1991).

Por último, en un nivel pragmático discursivo se consideró, también, el empleo de las fórmulas de ficción, en tanto indicador de conocimiento del tipo de texto, la narración.

\section{RESULTADOS}

El análisis de las producciones escritas permitió identificar diferencias importantes entre ambas condiciones. La tabla 1 muestra la media y el desvío estándar de la cantidad de categorías narrativas recuperadas y de la extensión de las producciones -medida en cantidad de palabras completas e intentadas-, en las dos condiciones de producción: la renarración $(\mathrm{CI})$ y el cuento producido a partir de imágenes (CII). 
Tabla 1

Medias y desvíos de la extensión y categorías narrativas recuperadas

\begin{tabular}{|l|c|c|c|c|c|c|}
\hline & \multicolumn{2}{|c|}{ Palabras completas } & \multicolumn{2}{c|}{ Palabras intentadas } & \multicolumn{2}{c|}{ Categorías narrativas } \\
\hline & CI & CII & CI & CII & CI & CII \\
\hline Media & 35.6 & 57.9 & 4.61 & 10.61 & 5.03 & 5.85 \\
\hline Desvío estándar & 25.6 & 30.2 & 4.96 & 14.54 & 2.9 & 2.5 \\
\hline
\end{tabular}

Como vemos en la tabla, los textos realizados a partir de imágenes (CII) eran más extensos y más completos que los realizados a partir de la narración oral (CI). En efecto, la extensión de las producciones a partir de imágenes supera ampliamente a la de los textos de la condición I. Esta diferencia es estadísticamente significativa $(\mathrm{t}=-4.368 ; \mathrm{p}<0.05)$. Por otro lado, para indagar si los textos eran más completos en una u otra condición, se contó la cantidad de categorías narrativas recuperadas. El análisis mostró una ventaja en las producciones de la CII, aunque en este caso la diferencia no fue estadísticamente significativa $(\mathrm{t}=-1.526 ; \mathrm{p}>0.05)$.

En cuanto a la cantidad de palabras intentadas, que constituyen un índice indirecto de la manera en que la transcripción puede afectar la producción incluso en el nivel de la escritura de palabras, los números muestran una mayor cantidad de palabras intentadas en la CII. Sin embargo, esta diferencia no resulta sorprendente en tanto que las producciones son más extensas. En este sentido, hemos calculado el porcentaje de palabras intentadas en cada condición, lo que podría precisar la magnitud de la diferencia. En efecto, advertimos que el porcentaje de palabras intentadas es mayor en la CII $(14,96 \%)$ que en la CI $(12,54 \%)$, aunque esta diferencia no es estadísticamente significativa $(t=1.106$; $\mathrm{p}=.277$ ). Es decir, en la escritura a partir de imágenes, las niñas no sólo escriben más palabras completas, sino que, en su intento por escribir relatos más completos, escriben también un mayor porcentaje de palabras con omisiones de letras.

Por otra parte, para el análisis de los mecanismos de cohesión se tuvo en cuenta la utilización de conectores, el empleo de los tiempos verbales y el mantenimiento de la cadena de correferencia.

En cuanto al empleo de los conectores se observó que, en ambas situaciones, los conectores más comunes fueron el nexo aditivo "Y" - de alta frecuencia en las producciones infantiles en general- y los conectores temporales. La presencia frecuente de marcadores de temporalidad resulta esperable por tratarse de una narración, lo que supone sucesión temporal de eventos relacionados.

En el empleo de estos conectores, no se advirtieron diferencias importantes entre situaciones, salvo por el empleo del conector "después", que en la CI se encontró sólo en dos textos, mientras que en la CII en 15 textos. Los marcadores de ruptura temporal -"de repente" / "de pronto"- tuvieron una frecuencia medianamente baja en ambas modalidades (siete textos en la CI y seis textos en la CII).

Las diferencias más importantes, sin embargo, se registran en el empleo de otro tipo de conectores. En efecto, en la Condición I no se encuentran nexos adversativos o causales, aunque un texto incorpora el nexo consecutivo "así que". En cambio, en la 
CII, en cinco textos aparece el adversativo "pero" y en seis textos el causal "porque", en todos los casos empleados de manera adecuada.

Esta diferencia puede explicarse, por una parte, por las restricciones, en tanto modelo linguiístico, que el texto de la CI ejercía en la tarea de renarración, ya que el texto fuente no incluía este tipo de conectores. Por otra parte, puede pensarse que en la CII, en la que el niño asume libremente el rol de narrador -no de "renarrador"- los niños tienen más posibilidades de introducir los conectores que consideran necesarios para contar la historia.

En relación con el empleo de los tiempos verbales no se observaron diferencias notables entre condiciones. En los textos se advirtió que predominaba la alternancia de pretérito imperfecto - para presentar el marco de la situación- y pretérito perfecto simple para presentar los acontecimientos que hacen avanzar la acción.

Sin embargo, en las producciones realizadas a partir de imágenes (CII) se encontraron tres textos en los que se alternaba el tiempo pasado y el tiempo presente en la narración de base, como se muestra en el ejemplo que sigue:

(1) "El tigre quiere hacer una trampa y la oveja estaba asustada y después salió el tigre y lo quería comer" (Luciana, CII).

En la CI, en cambio, ningún texto mostraba esta alternancia presente / pasado.

Asimismo, en la CII se encontraron dos textos escritos totalmente en presente. En estos textos el hilo narrativo se desdibuja y se observa una mera descripción de las imágenes, como en el ejemplo 2:

(2) ... “después lo atrampa y empieza a gritar la oveja lo mira al león como grita después la oveja lo mira al león y el león la mira la oveja al león y el león la mira a la oveja después se van como amigos los dos" (Milagros. CII).

En el ejemplo, la niña no cuenta cómo la oveja salvó al león en el segundo episodio, sino que se limita a describir lo que ve en las imágenes. El apoyo de las ilustraciones, en el caso de que no haya un vínculo causal fuerte entre las imágenes, puede conducir a que los niños produzcan este tipo de textos. No obstante, se trata de dos casos aislados en la muestra.

Por otra parte, en esta situación se observaron textos que incluyen el presente como parte del diálogo de los personajes:

(3) "Había una vez un león que tenía mucha hambre y dijo qué deliciosa oveja me la voy a comer quién está ahí dijo la oveja y de un salto el tigre la agarró y le dijo te voy a comer porque tengo mucha hambre no no no me comas por favor..." (Ayelén, CII).

En estos casos, el empleo del tiempo presente se utiliza para otorgarle la palabra a los personajes de la historia, recurso que da cuenta de una mayor libertad del narrador a la hora de narrar su cuento. En los textos de la condición I, no se encontró ningún caso similar, quizás porque los niños se ajustaban a la versión escuchada del texto fuente.

En cuanto al análisis de la cadena de correferencia, se advirtió que el índice de correferencia adecuado de la CII (0.88) fue mayor al de la CI (0.80), con una diferencia 
significativa $(\mathrm{t}=-3,300 ; \mathrm{p}=.003)$. No obstante, si bien estructuralmente los textos presentaban una complejidad similar, el cuento de la CI tenía tres personajes, del mismo género (león, elefante, tigre); por el contrario, el de la CII presentaba sólo dos personajes (león y cabrito). La diferencia en la cantidad de personajes reduce la dificultad del mantenimiento de referencia, hecho que podría explicar que el puntaje de la CII sea más alto. En este sentido, no parece posible plantear que la condición tenga una incidencia importante en el nivel de adecuación de la correferencia.

Por último, se atendió a la inclusión de fórmulas ficcionales, en tanto indicadores de un conocimiento pragmático comunicativo. En relación con este aspecto, se observó que la inclusión de la fórmula de inicio "había una vez" fue más frecuente en la CI que en la CII $(60,7 \%$ vs 42,86$)$. La diferencia entre ambas condiciones fue significativa $(\mathrm{t}=4.464 ; \mathrm{p}<0.05)$. Esta diferencia puede deberse a que en el texto fuente que se leyó en esta condición aparecía la fórmula "había una vez". Es posible que los niños se basen en el modelo para sus propias producciones.

En cuanto a la fórmula de cierre consideramos dos formas lingüísticas: "colorín colorado este cuento se ha terminado" y "vivieron felices para siempre" - esta última, mucho más frecuente en la muestra-. El empleo de la fórmula de cierre, contrariamente a lo esperado, fue mayor en las producciones de la CII (nueve casos) que en las de la CI (tres casos), aunque la diferencia no fue significativa $(\mathrm{t}=-2.766 ; \mathrm{p}>0.05)$. El hecho de que los niños incluyan en sus producciones fórmulas, cuando estas no estaban presentes en la historia utilizada como estímulo para la producción, sugiere que los niños conocen las fórmulas características del género y las perciben como elementos importantes de las historias.

\section{DISCUSION}

El análisis de los datos mostró, en términos generales, una ventaja importante de las producciones en la Condición II, los textos escritos a partir de una secuencia de imágenes. Estos resultados son contrarios a lo esperado, puesto que se consideraba que el facilitar a los niños un modelo de textualización -como era la narración oral- los ayudaría a producir textos más extensos y completos.

De hecho, en el trabajo realizado por Borzone y Marro (1990) se observó que los niños producían relatos más completos cuando reescribían un cuento leído. Cabe señalar que, en ese estudio, a diferencia del presente trabajo, en la condición de reescritura se recurrió a un cuento muy simple y breve y que, en la otra condición, se utilizaron las imágenes del libro de lectura que usaban los niños, que no ilustraban el cuento completo.

Las diferencias entre los resultados de Borzone y Marro (1990) y los obtenidos en nuestro trabajo, ambos realizados con niños hablantes de español, en los primeros años de escolaridad, constituyen un indicio para comprender la falta de consistencia observada en las investigaciones que abordaron la incidencia de la tarea en el desempeño oral (Pratt y Mac Kenzie-Keating, 1985; Gazella \& Stockman, 2003; Schneider, 1996; Schneider y Dubé, 1997, 2005). En estos trabajos, así como en el de Borzone y Marro y en el nuestro, se utilizaron distintos instrumentos para evaluar la producción discursiva. En este sentido, puede pensarse que el desempeño de los niños dependerá no sólo de la tarea que se compara, sino del input utilizado en cada caso. 
En efecto, en nuestro estudio, si bien el foco está puesto en la comparación de situaciones de escritura -a partir de un input lingüístico o de imágenes- cobra importancia también el tipo de input seleccionado.

En este caso, el input lingüístico no parece ser suficiente para aliviar la sobrecarga cognitiva del proceso de escritura cuando se trata de un texto extenso. A pesar de que proporciona un modelo lingüístico y narrativo, los niños no parecen poder retener en la memoria la representación mental que han formado y que constituye el contexto cognitivo para la escritura.

Por el contrario, cuando el proceso de escritura cuenta con el apoyo de una secuencia de imágenes que recupera todas las categorías de un cuento canónico -de manera tal que las relaciones causales entre eventos son fácilmente inferibles- y la secuencia de imágenes permanece a la vista del escritor durante todo el proceso, el desempeño de los niños es superior. En este sentido, las imágenes actúan como una representación mental que es fácilmente accesible, una forma de memoria externa que proporciona una referencia constante de contenido y planificación para el proceso de puesta en lenguaje.

Se podría pensar que las imágenes sesgan las producciones hacia una lectura de los dibujos, por lo que los niños harían descripciones de las ilustraciones más que narraciones. Sin embargo, encontramos sólo dos producciones de esta naturaleza. El fuerte vínculo causal entre las ilustraciones parece haber evitado ese sesgo. En efecto, la causalidad entre eventos sostiene la coherencia del relato (Trabasso, Secco y van den Broek, 1984).

Por otra parte, el orden en que se tomaron las pruebas puede haber incidido también en el desempeño. La prueba de renarración (Condición I) fue tomada una semana antes que la narración en la condición II. Si bien las historias eran diferentes, el parecido estructural podría haber generado un efecto de aprendizaje que incidiera en un mejor desempeño en la Condición II. En futuras investigaciones, esta variable debería ser controlada.

La versión oral que se les presentó a los niños -y que se pensó sería un apoyo más fuerte para la producción- parece restringir las posibilidades de narrar, puesto que los niños intentan ajustarse más fuertemente al modelo. Esta dependencia del modelo fue también observada por Schneider y Dubé (2005) con niños más grandes.

En otro orden de cosas, podría pensarse que se trata también de un posicionamiento diferente en cada situación. En la CI, los niños recuperan un texto escrito por otro en la CII, son ellos los narradores. Los niños, en esta condición, parecen tener más libertad discursiva.

En cualquier caso, la secuencia de imágenes, con fuertes vínculos causales entre sí, parece ser un recurso efectivo para andamiar la escritura. Se trata de una tarea que, al facilitar la producción escrita, les permite a los niños afianzar y ejercitar las operaciones implicadas en el proceso, de forma tal que puedan luego capitalizar estos aprendizajes en situaciones de escritura más demandantes. En este sentido, el apoyo de las imágenes para la escritura se configura como un dispositivo pedagógico valioso.

\section{REFERENCIAS BIBLIOGRAFICAS}

Bereiter, C. \& Scardamalia, M. (1987). The psychology of written composition. Hillsdale, NJ: Lawrence Erlbaum Associates.

Berninger, V. \& Swanson, L. (1994). Modifying Hayes and Flower's Model of Skilled writing to explain beginning and developing writing. In Butterfield, E. (ed.), Children's writing: toward a process theory of development of skilled writing (pp. 57-81), Greenwich, CT: JAL. 
Berninger, V., Yates, Ch., Cartwright, A., Rutberg, J., Remy, E. \& Abbott, R. (1992). Lower-level developmental skills in beginning writing. Reading and Writing: An Interdisciplinary Journal 4:257-280.

Borzone de Manrique, A.M. \& Marro, M.S. (1990). Lectura y escritura: nuevas propuestas desde la investigación y la práctica. Buenos Aires: Kapelusz.

Bourdin, B., Fayol, M. \& Darciaux, S. (1996). The comparison of oral and written modes on adults and children's narrative recall (pp. 159-169) Rijlaarsdam, G., van den Bergh, H. \& Couzijn, M. (eds.), Theories, Models and Methodology in writing Research. Amsterdam University Press.

Bruner, J. (1986). El habla del niño. Paidós: Barcelona.

Carrasco Gutiérrez, A. (1999). El tiempo verbal y la sintaxis oracional. La consecutio temporum (pp. 3061-3128), Bosque, I. y Demonte, V. Gramática descriptiva de la lengua española. Vol. 2. Madrid: Espasa-Calpe.

Gazella, J. \& Stockman, I.J. (2003). "Children's Story Retelling Under Different Modality and Task Conditions". Implications for Standardizing Language Sampling Procedures. American Journal of Speech-Language Pathology, Vol. 12, 61-72.

Hayes, J.R. \& Flower, L.S. (1980). Identifying the organization of writing process. In Gregg, L.W. \& Steinberg, E.R. (eds.). Cognitive processes in writing. Hillsdale, N.J., Lawrence Erlbaum.

Pratt, M. \& Mac Kenzie-Keating, S. (1985). Organizing stories: Effects of development and task difficulty on referential cohesion in narrative. Development Psychology, 21, 350-356.

Sánchez Abchi, V. (2009). El aprendizaje de la escritura en niños pequeños de medios rurales y urbanos. Un estudio de los subprocesos de transcripción y generación textual. Tesis Doctoral Inédita. Universidad Nacional de Córdoba. Argentina.

Sánchez Abchi, V. \& Borzone, A.M. (2007). "Los procesos de textualización: El uso de conectores en el inicio del aprendizaje de la escritura". Revista RASAL, de la Sociedad Argentina de Lingüística.

Sánchez Abchi, V., Borzone, A.M. \& Diuk, B. (2007). "La escritura de textos en niños pequeños: relación entre la transcripción y la composición”. Univ. Psychol., sept./dec. 2007, Vol. 6, № 3, p. 559-570. ISSN 1657-9267.

Schneider, P. (1996). "Effects of Pictures Versus Orally Presented Stories on Story Retellings by Children With Language Impairment". American Journal of Speech-Language Pathology Vol. 5, 86-96.

Schneider, P. \& Dubé, R. (2005). "Story Presentation Effects on Children's Retell Content". American Journal of Speech-Language Pathology, Vol. 14, 52-60.

Schneider, P. \& Dubé, R. (1997). Effect of pictorial versus oral story presentation on children's use of referring expressions in retell. First Language, Vol. 17, No 51, 283-302 (1997) DOI: $10.1177 / 014272379701705113$.

Sebastián, E. \& Slobin, D. (1994). Development of linguistic forms: Spanish. In Berman, R. \& Slobin, D. (eds.), Relating events in narrative: A crosslinguistic developmental study. Hillsdale, NJ: Erlbaum. 239-284.

Sebastián, E. (1991). El desarrollo del sistema de referencia temporal en español: Un paseo por la morfología verbal. Anales de Psicología. 7 (2), 181-196.

Stein, N.L. \& Glenn, C.G. (1979). An Analysis of Story Comprehension in Elementary School Children. En Freedle, R.O. (ed.), New Directions in Discourse Processing (Vol. 4, pp. 53-120). Norwood, NJ: Ablex.

Trabasso, T., Secco, T. \& van den Broek, P. (1984). Causal cohesion and story coherence. En Mandl, H., Stein, N. \& Trabasso, T. (eds.), Learning and comprehension of text (pp. 83-111). Hillsdale, NJ: Erlbaum. 